\title{
PATHOS E ARGUMENTAÇÃO COMO EMPODERAMENTO NO RAP
}

\section{PATHOS AND ARGUMENTATION AS EMPOWERMENT IN RAP MUSIC}

\author{
Bruna Fernandes Barros (UFSJ/FAPEMIG) ${ }^{1}$
}

\begin{abstract}
RESUMO
O presente trabalho tem como objetivo identificar e analisar a argumentação por meio do estudo das emoções, aplicando as categorias de análise da patemização do discurso propostas por Charaudeau (2010) no rap, mais especificamente nas músicas Bate poeira e Você não vai, de Karol Conka. O objeto de análise foi escolhido tanto devido ao caráter subversivo do movimento hip hop (ao qual o rap pertence), quanto à forma de construção do próprio ritmo, que utiliza raciocínio rápido e lógico para elaboração de suas letras. O debate acerca de questões étnicas, de gênero e sociais na música de Conka foi o fator fundamental para a seleção das canções a serem analisadas. Neste trabalho, situaremos o hip hop historicamente e abordaremos a noção de pathos na argumentação para, assim, analisar o objeto. Entendemos que esse estudo se faz necessário a fim de compreender como as emoções e o possível despertar destas no público pode funcionar a fim de persuadir e/ou difundir uma ideia.
\end{abstract}

PALAVRAS-CHAVE: hip hop, argumentação, emoção, pathos

\begin{abstract}
This work aims to identify and analyze the argumentation through the study of the emotions, applying the categories of analysis of the discourse patemization proposed by Charaudeau (2010) in rap music, more specifically in the songs Bate Poeira and Você não Vai, by Karol Conka. The object of analysis was chosen both because of the subversive attitude of hip hop movement (to which rap belongs), and the way of constructing the rhythm itself, which uses fast and logical reasoning to elaborate it's lyrics. The debate about ethnic, gender and social issues in Conka's music was the key factor in the selection of these songs. In this work, we situate hip hop historically and approach the notion of pathos in the argumentation in order to analyze the object. We understand that this study is necessary in order to understand how the emotions and the possible awakening of these in the public can work in order to persuade and spread an idea.
\end{abstract}

KEYWORDS: hip hop, argumentation, emotion, pathos

\section{INTRODUÇÃO}

A argumentação pode ser vista como uma forma de buscar persuadir um público, pode ter como objetivo gerar consenso ou adesão em torno de uma tese apresentada (SOUZA, 2001). Entendemos neste trabalho que para além de textos claramente argumentativos, como em geral os textos políticos, outras formas de comunicação utilizam a argumentação para seu fim de maneira mais sutil, estando assim situadas em algo como um espectro argumentativo. No entanto, devemos considerar que nem todo texto necessariamente tem o objetivo de convencer direta ou indiretamente:

Nem toda informação visa intencionalmente a influenciar um auditório. $\mathrm{O}$ ato de responder a uma pessoa que nos pergunta as horas dificilmente (salvo má fé) inclui um

\footnotetext{
${ }^{1}$ Mestranda do Programa de Pós-Graduação em Letras: Teoria Literária e Crítica da Cultura da UFSJ. Bolsista FAPEMIG. Pósgraduada em Gestão de Pessoas e Recursos Humanos pela Faculdade FACED. Graduada em Comunicação Social - Publicidade e Propaganda pela Universidade do Vale do Itajaí. E-mail: brunafbarros@live.com
} 
fim de influência sobre sua crença no tempo. Por outro lado, situações marcadas por conflitos de posições e de crenças, onde virtuais ganhos e vantagens se encontram em jogo, implicam uma outra maneira de ver as coisas. Nesses casos, não estamos na presença de uma simples intenção informativa, pois o roteiro da comunicação se torna bastante importante na realização de ganhos e vantagens. (SOUZA, 2001, p. 157)

Existem textos que possuem claramente o convencimento como seu objetivo final, mas também há textos que não podem ser encaixados nessa lógica, como uma informação sobre o clima, por exemplo. Para além desses dois cenários, há um entremeio, é possível identificar textos em uma dimensão argumentativa (AMOSSY, 2017), os quais não atuam de forma direta para persuadir o público, seu objetivo final pode ser outro, mas o convencimento se mostra como um desdobramento. Assim podemos observar determinadas músicas, o foco de uma música em geral não é persuadir, mas, por vezes, pode produzir um efeito de sentido a fim de gerar adesão a um tema, utilizando também a emoção. Dentro deste nicho, o rap ou hip hop, com suas metáforas, críticas sociais e agilidade na construção da lógica e rimas, talvez seja um dos estilos musicais que mais explore técnicas argumentativas em suas letras.

O objetivo deste trabalho é identificar e analisar as estratégias argumentativas patêmicas nas letras das músicas Bate Poeira e Você não vai, de Karol Conka, utilizadas a fim de defender sua tese de empoderamento do subalterno. Neste estudo, utilizamos o conceito de empoderamento como DEERE e LEÓN (2002), os quais o definem como um processo em que o sujeito toma o poder sobre sua vida e, dessa forma, possa definir como quer atuar. Existe certa associação do empoderamento com a emancipação pessoal. Empoderar-se pode ser revolucionário para a vida particular e coletiva.

A música, como as artes em geral, busca tocar, causar uma emoção. No rap, muitas vezes, essa emoção se dá por meio de um relato argumentativo, uma forma de diálogo no qual o interlocutor é presumido, não-presente. O sentimento despertado pela canção pode não necessariamente ser positivo, pode ser angustiante a fim de causar uma reação pela revolta, ou ainda gerar certa empatia por meio de uma reflexão do que é cantado. Devido a isso, mesmo estando ciente dos três aspectos da argumentação (Ethos, Pathos, Logos), esse trabalho se propõe a analisar a argumentação por meio da emoção (Pathos).

O hip hop, originalmente, configura-se como um movimento de resistência pela criatividade, sendo o rap pertencente a este. Em diferentes partes do mundo, o movimento nasce por meio de jovens das periferias com o fim de criar e se manifestar por meio da arte, com o break dance, o rap, $D J s$, e o grafite. Rappers em geral utilizam a música e as letras para desenvolver uma forma de conversa com textos do senso comum, debatendo e argumentando com linhas de pensamentos postas na sociedade, a fim de gerar comoção e reflexão social. Karol Conka possui este perfil, as temáticas de suas músicas envolvem, principalmente, questões da mulher e da periferia. Conka adquiriu visibilidade nacional com seu álbum Batuk. Freak (2013). As músicas Bate Poeira e Você não vai pertencem a este álbum e abordam questões socialmente relevantes, como empoderamento, racismo e desigualdade social.

Para analisar as músicas de Karol Conka em sua escala argumentativa, utilizamos a noção de Charaudeau (2007) de patemização no discurso. A princípio, apresentamos o percurso histórico do hip hop destacando seu posicionamento de resistência e luta por meio das palavras. No segundo momento, discorremos brevemente sobre a argumentação a fim de indicar os caminhos até a delimitação de análise pelo pathos. Por fim, analisamos o objeto selecionado pelo método de Charaudeau.

\section{A construção do hip hop}

O movimento hip hop carrega em si as marcas da resistência, surge na periferia como forma de expressão e subversão. Souza (2009) remonta o movimento desde a Jamaica dos anos 1920 e 
1930, quando um grande número de jovens pobres migra da zona rural para as cidades a fim de buscar ascensão social. De acordo com Magro (2002), o hip hop se prolifera nos Estados Unidos na década de 1960, época em que jovens negros e latino-americanos das periferias se unem para se manifestar por meio da criação autoral de diferentes formas, como o próprio rap. No Brasil, o movimento também teve seu início na periferia, como explica Herschman (2005, p. 25):

\begin{abstract}
O hip-hop "nacional” surgiu, em meados da década de 80, nos salões que animavam a noite paulistana no circuito negro e população dos bairros periféricos e contou, nos seus primeiros eventos, com a forte presença de grupos norte-americanos e alguns expoentes brasileiros. Mobilizando no início apenas a juventude negra e trabalhadora da cidade, o hip-hop hoje está organizado em grupos, associações, "posses" e pequenas gravadoras, vem difundindo-se e atraindo boa parte da população jovem e constitui importante segmento de mercado.
\end{abstract}

A cultura hip hop no Brasil se ampliou aos poucos, por meio da sua arte crítica o movimento gradualmente ganhou espaço em outros setores, inclusive na indústria fonográfica. A NIELSEN (2017) divulgou em sua pesquisa anual o crescimento do hip hop (nomeado na pesquisa como a combinação de $R \& B e$ Rap) que, pela primeira vez na história, se tornou o estilo musical mais ouvido do ano, ultrapassando o tradicional Rock.

O percurso do movimento hip hop se combina ao do funk no sentido de serem ritmos periféricos, produzidos e destinados em maior parte à população negra e pobre no Brasil. Assim como o funk, o hip hop brasileiro teve suas origens no soul norte-americano e ambos nasceram em áreas periféricas. No entanto, no Brasil, em meados dos anos de 1970 e 1980, o funk recebeu uma roupagem diferente no Rio de Janeiro, sem necessariamente carregar o perfil engajado politicamente, e o hip hop se situou nos bairros pobres de São Paulo (HERSCHMAN, 2005).

Funk e hip hop passam a se distanciar em tópicos relacionados à política e questões sociais, "os b-boys ${ }^{2}$ e outros grupos que se alinham ao movimento negro (como os charmeiros) acusam o funk de produzir uma música despreocupada, que promove apenas o entretenimento." (HERSCHMAN, 2005, p. 28). Mesmo com essa diferenciação característica, não seria adequado dizer que o funk é apolítico, mas é o hip hop que faz desse posicionamento o tema de muitas de suas letras. O rap nasce quase como um poema com batidas de fundo, e essa batida pode ser produzida inclusive com sons feitos com a boca, o que é conhecido como beatbox. É a letra que conduz o rap, a importância da construção verbal, da coerência e da argumentação desse estilo musical são fundamentais para tocar o público e em certa medida convencê-lo.

O Brasil que recebe o hip hop na transição das décadas de 1970 para 1980 se encontra em quase duas décadas de ditatura militar, com intensa repressão a movimentos populares. Neste momento, o número de desempregados é grande, a inflação cresce e movimentos sindicais, populares e organizações se manifestam (SOUZA, 2009). O momento histórico do surgimento do hip hop no Brasil pode ter intensificado a indignação nas periferias e, com isso, ter despertado a necessidade de canalizar essa insatisfação de forma criativa.

Karol Conka declara abertamente em entrevistas seu posicionamento feminista, sua adesão ao movimento negro e também relata o preconceito vivido (BOCK, 2018). Esses temas aparecem nas letras de suas músicas, dividindo espaço com raps que tratam do dia a dia do trabalhador, fazem referências a religiões de matriz africana e também falam sobre festa e diversão.

A rapper é curitibana, bissexual, negra e mãe solo desde os 19 anos, quando já dava os primeiros passos no hip hop (BOCK, 2018). Em 2013, com o lançamento de seu primeiro álbum de estúdio, a cantora despontou para o grande público, ganhando seu primeiro prêmio de alcance nacional, Artista Revelação no Prêmio Multishow de Música Brasileira. Atualmente, trabalha na

\footnotetext{
2 B-boys para HERSCHMAN (2005, p.19) é uma "forma de designar o público do hip-hop, ou seja, aqueles que fazem parte dessa cultura".
} 
divulgação de seu segundo álbum e também atua como apresentadora do programa Superbonita, do canal de TV por assinatura GNT.

\title{
2 Argumentação e a patemização no discurso
}

A tradição da retórica na argumentação, para os sofistas, significava defender ou se opor a qualquer tese, era preciso apenas que fosse trabalhada a oratória para o sucesso do convencimento. Para Souza (2001, p. 163), Aristóteles buscou uma outra forma de desenvolver a argumentação:

\footnotetext{
Para que uma tese consiga adesão de um auditório, ela necessita, de certa forma, estar em conformidade com as crenças desse auditório ou, a fortiori, com o que esse auditório é capaz de admitir como sendo racional. A relação entre o orador (locutor) e o auditório (receptor) torna-se assim essencial. (...) A relação fundamental, que associa o orador e seu auditório numa certa dimensão de conivência e regulação, encontra-se presente na maioria dos trabalhos modernos sobre a comunicação humana.
}

Nos estudos de Aristóteles, segundo Souza (2001), a oratória não se basta em si mesma, é necessário que o argumento esteja de acordo com as crenças do interlocutor a quem se busca persuadir ou que, ao menos, este considere a lógica utilizada como racional. A fim de articular a argumentação, Aristóteles também concebe os conceitos de Ethos, a imagem do orador, Logos, a organização do discurso, e Pathos, as possíveis emoções despertadas no interlocutor (SOUZA, 2001). É a este último aspecto que nos atemos neste trabalho, considerando a capacidade da música de despertar sentimentos e emoções como estratégia argumentativa.

A argumentação desenvolvida com o fim de gerar reflexão por meio da emoção pode atuar como um modo de reconstruir ideias apresentadas como verdades naturais, esta estratégia pode ser observada no movimento hip hop. A música é um desses veículos que pode conduzir o a análise e o pensamento crítica. Por meio de canções, sua melodia, letra e as emoções despertadas é possível oferecer uma outra visão de mundo, fora dos padrões socioculturais estabelecidos. Isso aconteceu no Brasil da ditadura militar, com a MPB, quando era necessário denunciar a opressão social, a censura e a violência instauradas pelo governo, tudo isso de forma velada, até certo ponto. Também foi visto no rock dos anos de 1980, com bandas denunciando a desigualdade social e a corrupção na política brasileira em suas letras.

Entretanto, não podemos identificar essa articulação musical como uma retórica simples e direta. A fim de compreender os caminhos da argumentação na música trazemos o conceito de dimensão argumentativa, de Amossy (2017, p 132):

\begin{abstract}
As coisas apresentam-se, diferentemente, no caso da dimensão argumentativa, em que a estratégia de persuasão é indireta e, muitas vezes, não admitida. Ela aparece na verbalização que produz um discurso cujo objetivo declarado é outro e não o argumentativo: um discurso de informação, uma descrição, uma narração cuja vocação é contar, o registro de uma experiência vivida em um diário de viagem ou um diário, um testemunho que relata o que o sujeito viu (...). Portanto, o que é importante é identificar e analisar a maneira como esses discursos destinados a, antes de tudo, informar, descrever, narrar, testemunhar, direcionam o olhar do alocutário para fazê-lo perceber as coisas de uma certa maneira.
\end{abstract}

A autora concebe a dimensão argumentativa em uma forma de desdobramento da intenção de persuasão. Esta reuniria estratégias lógicas e estruturadas com o fim último de convencer o interlocutor, enquanto aquela teria a adesão à tese apresentada como um possível efeito e não necessariamente como seu objetivo absoluto. No rap, as denúncias sociais se ampliam abrangendo questões étnicas, com o desvelamento do racismo, e de gênero, por meio de rappers feministas. No entanto, não é possível afirmar que o principal objetivo de um estilo musical é 
persuadir, mas podemos entender que o diálogo desenvolvido pelo rap pode levar à reflexão e, em certo nível, buscar adesão aos diferentes temas abordados.

Para Charaudeau (2008, p. 205), "O sujeito que argumenta passa pela expressão de uma convicção e de uma explicação que tenta transmitir ao interlocutor para persuadi-lo a modificar seu comportamento". O rap, com seu apelo crítico, atua como uma forma de resistência discursiva ao que é posto e busca por meio das palavras na argumentação causar mudança social em certos níveis. Não há, no geral, uma chamada imperativa à ação na música, mas pode existir a tentativa de modificar ideias e comportamentos por meio da reflexão e da comoção.

A fim de abordar a emoção no discurso, Charaudeau utiliza a ideia de Pathos da argumentação e elabora um método de análise das emoções na linguagem. $\mathrm{O}$ autor trabalha com a noção de que "as emoções são de ordem intencional, estão ligadas a saberes de crença e se inscrevem em uma problemática da representação psicossocial." (CHARAUDEAU, 2010, p. 2). Ou seja, as emoções partem de uma forma de lógica, uma racionalidade em um nível individual, pois nossas vivências são particulares. Mas também nascem de uma razão social comum, no sentido em que compartilhamos como sociedade uma cultura e uma moral que influem em nossas crenças e ações.

Destarte, a emoção surge de um pensamento que dita o que devemos sentir em cada acontecimento, este nem sempre é perceptível já que em geral não é habitual parar e analisar o percurso de cada emoção. Mas um pensamento também pode suceder de uma emoção (CHARAUDEAU, 2010). Se nos sentimos angustiados com algo que consideramos injusto, podemos partir para uma análise dos conceitos e cenários que permitiram tal injustiça. Neste sentido, podemos ver a utilização das emoções no discurso como uma forma de tentativa de convencimento, um método para motivar determinado pensamento ou comportamento individual ou coletivo.

Pensar emoção na linguagem pode ser problemático se consideramos a subjetividade dos sentimentos e como estes podem se mostrar de uma forma, mas essencialmente significar outra para quem o expõe. Tratando de análise do discurso, não é possível nos apegarmos à intenção do sujeito, mas sim aos efeitos de sentido que a linguagem pode provocar. Por isso, analisar a emoção na linguagem é identificar os possíveis efeitos de sentido provocados. A fim de ser analisada discursivamente "a emoção é considerada fora do vivenciado, e apenas como um possível surgimento de seu "re-sentido" em um sujeito específico, em situação particular." (CHARAUDEAU, 2010, p. 5).

Charaudeau (2010) destaca três aspectos prévios a serem observados na análise patêmica do discurso: situação de comunicação (1), universos de saber partilhado (2), estratégia enunciativa (3). No primeiro, é preciso observar tudo o que constitui a cena enunciativa, onde estão os sujeitos e como se comportam neste ambiente seriam algumas perguntas a se fazer para compreender a situação de comunicação. No segundo, é necessário conhecer os sujeitos envolvidos na enunciação para entender quais crenças, noções de moral e conhecimento que eles compartilham e o que pode falhar nessa comunicação. Por fim, o terceiro aspecto se refere às formas utilizadas pelo locutor de capturar seu público.

Charaudeau (2007, p. 245) afirma que "o sujeito falante recorre a modos de organização discursiva seguindo uma racionalidade tanto narrativa quanto argumentativa ao mesmo tempo em que lança a hipótese na qual outro poderá reconhecê-los e aderir a eles.”. Este é o cenário da produção musical, um trabalho que envolve letristas, instrumentistas e produtores em um longo processo de estudo e criação. O próprio ato do rapper que elabora sua composição reflete tais características.

Com o fim de identificar e analisar os traços de argumentação pela emoção na música de Karol Conka, aplicaremos as categorias nomeadas por Charaudeau (2010) como tópicas do Pathos: 
- Dor/Alegria - Nesta categoria é observado, por um lado, o desejo não satisfeito ou o sentimento de humilhação (Dor) e a satisfação, o orgulho e até o empoderamento (Alegria). Identificamos nos raps de Conka essa oposição, principalmente, no preconceito e em sua superação.

- Angústia/Esperança - Aqui, a angústia surge como uma emoção que contém medo, incertezas e desamparo e a esperança como um símbolo de confiança e expectativa. Nas músicas analisadas, a angústia se faz presente em situações cotidianas, enquanto seu oposto surge quando se emprega um novo olhar sobre tais acontecimentos.

- Antipatia/Simpatia - A antipatia se revela como indignação, reprovação dos atos de alguém, enquanto seu contraponto, a simpatia, é a compaixão, a conexão feita com algo ou alguém, associando aquele a si mesmo. O alguém foco da antipatia nos raps analisados é justamente aquele que articula atitudes e ideias conservadoras e preconceituosas, enquanto a simpatia é direcionada para a diversidade e o poder das minorias simbólicas.

- Repulsa/Atração - Esta categoria traz a repulsa, que é motivada pela aversão ou desprezo, e a atração, que pode criar um tipo de herói a partir da admiração. A repulsa, nas músicas analisadas, surge em adjetivos direcionados a ideias repressoras, enquanto a atração é o enaltecimento de si ou de seu grupo.

É importante destacar que Charaudeau desenvolveu estas categorias com base em seus estudos das mídias, quando as deslocamos para a música, mais especificamente para o rap, elas podem obter ou se desvencilhar de certas características.

\section{Análise: A emoção e a comoção no hip hop}

As músicas Bate Poeira e Você não vai, apesar de lançadas oficialmente em 2013, no álbum Batuk Freak, mantêm-se atuais, desvelando debates frequentes e necessários na sociedade brasileira, como preconceito e desigualdade social. Em 2017, Bate Poeira foi trilha de abertura da série adolescente Malhação - Viva a diferença na TV Globo, o que também confirma a relevância da canção na atualidade. Este é um rap que fala de preconceito, exclusão e superação como forma de libertação de padrões estéticos, apresenta intensidade e sentimento ao tratar do tema da diferença e como esta pode ser desenvolvida positivamente na sociedade. Por outro lado, Você não vai, apesar de também tratar de empoderamento e preconceito, surge de um lugar mais confiante e não trata diretamente de questões estéticas. $\mathrm{Na}$ análise, faremos a transcrição linear das músicas Bate Poeira e Você não vai, respectivamente, excluindo apenas a repetição de trechos, como o refrão.

De acordo com as definições já abordadas de Charaudeau (2010), podemos considerar como situação de comunicação a letra da música em si e seus possíveis efeitos de sentido. Entendemos que os universos de saber partilhado são a realidade brasileira tratada nas canções: o preconceito racial e estético, as diferenças sociais e talvez, inclusive, a cultura bip hop. A estratégia enunciativa é argumentar em favor das diferenças e em detrimento da homogeneização estética, em Bate Poeira, e contra o preconceito e a desigualdade social em Você não vai. Os temas abordados em ambas as músicas contribuem para defender a tese de empoderamento do "excluído", daquele que está fora dos padrões sociais e estéticos. Como já dito, não vamos nos ater a um sentido "real", mas a efeitos de sentido, analisaremos as letras das músicas em si, com o foco na própria linguagem trabalhada e não no que ela tenha despertado no ouvinte, o que seria impossível saber com exatidão.

No início da música Bate Poeira, podemos identificar as tópicas Antipatia/Simpatia. A cantora utiliza as primeiras frases para apresentar a proposta do rap e o posicionamento que terá no decorrer da letra.

\section{Os perturbados se prevalecem}


2. Enquanto atingidos adoecem

3. Palavras soltas que aborrecem

4. Esperança depois de uma prece

Nas frases 1, 2 e 3 a Antipatia se mostra numa espécie de embate, ao utilizar palavras como "prevalecem" e "atingidos", a rapper faz alusão a um combate físico. Quando menciona o grupo opressor dessa luta como "perturbados", Conka demonstra não só seu desagrado, como expõe sua ideia de certo e errado e oferece um vislumbre de como irá desconstruir a soberania do padrão estético vigente: desvelando a incoerência deste padrão e de quem o perpetua. A seguir a tópica identificada se mantém com seu polo oposto, a Simpatia, que parece buscar aproximar o público da tese defendida:

5. Um povo com crise de abstinência

6. Procura explicaşão pra existência

7. Num mundo onde dão mais valor pra aparência

8. Tem sua consequência

No trecho acima, a rapper demonstra sua empatia por quem está fora dos padrões de beleza. A partir deste ponto a problemática abordada na letra se torna mais clara e é reforçada no decorrer do próximo excerto:

9. Negro, branco, rico, pobre

10. O sangue é da mesma cor

11. Somos todos iguais

12. Sentimos calor, alegria e dor

13. Krishna, Buda, Jesus, Allah

14. Speed Black profetizon

15. Nosso Deus é um só

16. Vários nomes pro mesmo criador

17. Pouco me importa sua etnia

18. Religião, crença, filosofia

19. Absorvendo sabedoria

20. Desenvolvendo men dia-a-dia

Nesta sequência, podemos identificar mais de uma tópica do polo positivo das emoções, a Simpatia se mostra nas linhas 9 a 16, com expressões como "o sangue é da mesma cor", "somos todos iguais" e "nosso Deus é um sô" a cantora se inclui no grupo dos diferentes, daqueles fora do padrão. Ao utilizar o pronome pessoal da primeira pessoa do plural, Conka demonstra empatia e se inclui na diversidade popular. Essa estratégia argumentativa pode atuar com o fim de fortalecer aquele que não está no centro do poder, mas à margem dele. A partir da linha 17 , podemos observar a tópica Atração, nestes versos a cantora enaltece o grupo alvo da canção (os diferentes, fora do padrão de beleza) e, ao associar o diferente com conhecimento e crescimento, pode se conectar com o grupo em questão. A rapper se mostra atraída por este público ao mesmo tempo em que busca o atrair.

21. Nesse mundo poucas coisas são certas

22. Amor, sorte, morte, a vida que se leva

23. Do sul para o norte, da Ásia à América

24. Se errar é bumano o erro te liberta 
No trecho acima, Karol Conka utiliza a imprevisibilidade da vida para argumentar a favor das diferenças, atribuindo um caráter humano e positivo ao que pode ser considerado erro. Podemos identificar nesta sessão a tópica Esperança se opondo a Angústia. Estar fora do padrão, ser um "erro" poderia ser um fator angustiante, mas por um outro olhar essa falha é o que te constrói e pode te elevar e oferecer esperança, "se errar é bumano o erro te liberta". No refrão, a seguir, a cantora desenvolve o pensamento que atinge seu auge na tópica da Alegria:

25. Seja o que tiver que ser, seja o que quiser ser

26. Bate a poeira, bate a poeira, bate a poeira

27. Seja o que quiser ser

28. Bate a poeira, bate a poeira, bate a poeira

29. Seja o que tiver que

O orgulho e a busca pelo empoderamento estão presentes tanto na chamada a liberdade de ser, como na frase título da música "Bate a poeira", o que seria o equivalente ao também popular "dar a volta por cima". Tais colocações conversam com o ouvinte de forma casual, utilizando a linguagem informal, como o título que referencia uma expressão popular. O otimismo marca a argumentação ("Seja o que quiser ser ") e se mostra como uma estratégia para aproximar o público da tese defendida neste rap.

30. O preconceito velado

31. Tem o mesmo efeito, mesmo estrago

32. Raciocinio afetado

33. Falar uma coisa e ficar do outro lado

34. Se o tempo é rei vamos esperar a lei

35. Tudo que já passei nunca me intimidei

36. Já sofri, já ganhei, aprendi, ensinei

37. Tentaram me sufocar mas eu respirei

A partir da linha 30 podemos identificar traços da tópica Dor: "O preconceito velado/ Tem o mesmo efeito, mesmo estrago". Conka conta em primeira pessoa, nas linhas 35 e 36, o próprio sofrimento, relata humilhação, mas também seu oposto, a superação, satisfação que pode ser vista como a tópica Alegria: "Tentaram me sufocar mas eu respirei". O trecho pode criar certa aproximação com ouvintes que passaram por acontecimentos e sensações similares, é uma estratégia argumentativa patêmica, que gera a empatia pela emoção despertada na memória coletiva de um grupo.

38. Há tanta gente infeliz.

39. Com vergonha da beleza natural

40. É só mais um aprendir.

41. Que se esconde atrás de uma vida virtual

42. Gorda, preta, loira o que tiver que ser

43. Magra, santa, doida somos a força e o poder

44. Basta, chega, bora, levanta a cabeça e vê

45. Vem cá, viva, sinta, o que quiser você pode ser

Ao fim da letra identificamos as tópicas Repulsa e Atração em dualidade no trecho. A rapper volta a descrever de forma negativa ("gente infeliz", "se esconde") quem repreende a diversidade, distancia-se em repulsa dessa ideia. Por outro lado, traz novas características para os diferentes que admira e convida a todos à auto apreciação ("Magra, santa, doida somos a força e 
o poder"). Em mais um movimento empoderador, Conka cita diretamente as características das pessoas que busca enaltecer. Dizer "gorda" ou "preta" não só declara a beleza das diferenças, mas funciona como um mecanismo de reapropriação de palavras tidas como negativas para ressignificar seu valor e seu sentido.

Sequencialmente, na letra de Você não vai, identificamos a tópica Antipatia construindo o personagem virtual com quem a rapper dialoga na música. Nas falas "você me subestima" e "se apavora ao ver que cada vez mais posso progredir", a cantora estabelece o embate com um alguém ou uma fala que busca inferiorizá-la, mas não consegue. A tópica Simpatia pode ser apontada no verso "Herdeira dos meus ancestrais, cultivando a paz, que o verde me traz", no qual Conka se aproxima de sua origem africana, da natureza e demarca a fonte da sua força pessoal. Assim como em Bate Poeira, a rapper dialoga com textos e preconceitos postos na sociedade, sem os citar diretamente, mas é a partir desse movimento de debate que a argumentação pelo Pathos se desenvolve.

1a. Você me subestima, eu continuo nem aí

2a. Vivo na brisa e o que me incomoda deixa de existir

3a. Se apavora ao ver que cada vez mais posso progredir

4a. Passa, ignora e percebe que não tem pra onde fugir

5a. Vejo você cair, querendo admitir

6a. Que o men processo apesar de ser lento pode fluir

7a. Herdeira dos meus ancestrais, cultivando a paz, que o verde me traz.

8a. Espalho minha mensagem e nada mais

As tópicas Dor/Alegria são identificadas nos próximos versos, a partir da linha 10a. Nesta letra, a confiança da cantora está estabelecida, a Dor apontada acontece no outro, este indivíduo virtual com quem a rapper debate na música, identificada na frase "enquanto meu flow te enlouquece". Em contraponto, a Alegria é observada em vários momentos, como no orgulho de "Meu poder é black/Te provo tudo isso no rap" ou na tranquilidade de "Vou bebendo um domecq, enquanto meu flow te enlouquece". A cantora também enaltece sua posição ainda na tópica da Alegria quando afirma "Nessa vida não basta querer ser/ Tem que tá na veia, saber fazer". Com a associação desta frase (17a) com a referência da ancestralidade (7a) e do poder black (10a), a construção do sentido de força pode ser associada não só à própria Conka, mas a um grupo específico, o qual a rapper busca elevar e empoderar, que seriam os negros e a periferia.

9a. Você parece que esquece que eu não uso estepe

10a. Meu poder é black

11a. Te provo tudo isso no rap

12a. Se duvida aperta o rec, beat do nave me aquece

13a. Vou bebendo um domecq, enquanto meu flow te enlouquece

14a. Você demorou muito tempo pra perceber

15a. Que ficar me julgando só te levou a perder

16a. Nessa vida não basta querer ser

17a. Tem que tá na veia, saber fazer

A partir da linha 18a, observamos as tópicas Repulsa/Atração em determinados versos. A Repulsa se destaca em passagens como "Esse seu jeito vulgar" e "Cala essa boca e tenta entender", nas quais identificamos a contínua construção desse ser opositor virtual como alguém desprezível e ignorante. Esse movimento de desqualificar o adversário pode funcionar como uma estratégia argumentativa emocional com o fim de envolver o público nas suas ideias, gerando 
identificação pela posição intelectualmente superior que coloca para si. Essa estratégia é identificada nas duas músicas analisadas.

18a. Mas você se distrai, confunde o meu valor

19a. Sai falando demais, fica puto enquanto eu vou

20a. Pronde você não vai, você não vai

21a. Mais uma vez derrubei, estilo fera pronta pra atacar

22a. Eu te avisei que me garanto e não tô pra brincar

23a. Tenta me desafiar e veja aonde vai parar

24a. Com certeza não é o mesmo lugar que eu vou estar

25a. Tô tentando entender

26a. Esse seu jeito vulgar que tem ao dizer

27a. Como devo caminhar e o que devo fazer

28a. Se quer saber, não vale a pena gastar proceder

29a. Só observa como eu faço

30a. Cala essa boca e tenta entender

A Atração se mostra nos destaques feitos em primeira pessoa a partir da linha 21a: "Mais uma vez derrubei, estilo fera pronta pra atacar", "Com certeza não é o mesmo lugar que eu vou estar", "Só observa como eu faço". Em todas estas frases o objetivo é engrandecer o 'eu' em detrimento do 'outro'. Esse embate verbal pode funcionar dualmente, tanto para criar atração ao 'eu' e, logo, a sua tese, quanto para despertar a repulsa ao outro. No entanto, este 'eu' não é necessariamente a persona da cantora, mas possivelmente um grupo, a parte da sociedade que ela busca representar, os negros, os pobres, aqueles que estão numa luta metafórica diária, contra a desigualdade e contra o preconceito.

31a. Preparada, eu vou para onde en quiser

33a. Meto os meus pés na estrada e enfrento o que vier

34a. Justamente por ser mulher, e não ser uma qualquer

35a. Minha atitude carrega vitória

36a. Vou te lembrar disso sempre que eu puder

Ao fim da canção, a rapper traz a tópica Alegria associada ao empoderamento, enaltecendo sua posição, sua força e, consequentemente, a de todos aqueles que se identificam com o que busca representar. $\mathrm{Na}$ linha 34a, Conka referencia um comentário machista ("uma qualquer") e o desconstrói a fim de elevar a posição feminina, encerra reafirmando a posição de superação (linha 35a) e a necessidade constante de reafirmação social (36a).

Por fim, podemos observar nas duas músicas analisadas o emprego da argumentação patêmica em seu desenvolvimento. A emoção é articulada ao aproximar o interlocutor de possíveis acontecimentos sensíveis ao público com o provável fim de comover e, em certo nível, convencer o ouvinte da força da tese defendida.

\section{CONSIDERAÇÕES FINAIS}

Argumentar dificilmente pode ser associado exclusivamente a um processo lógico. Ao considerarmos um mundo com inúmeros estímulos sensoriais, seria provavelmente ineficaz buscar convencer alguém pela razão e pela lógica sem considerar suas vivências e, logo, suas emoções. A arte em geral parece ter essa habilidade transformadora por meio das emoções, mas não porque busca convencer diretamente e sim porque tende a comover e ter o convencimento como um possível desdobramento. 
A música engajada em questões sociais pode despertar empatia e identificação em grupos subalternos, além de gerar reflexão em sujeitos distanciados da realidade dessas minorias simbólicas. Esse processo pode ser mais complexo do que o convencimento pela argumentação puramente lógica, pois compreende o envolvimento do outro pela emoção, pelo pathos, e pode culminar em uma forma de transformação social. Podemos identificar essa característica nas letras analisadas dos raps de Karol Conka.

Se a emoção passa pelo âmbito do pensamento, a argumentação pelo pathos pode ter um efeito real na construção e reinvenção dos sujeitos. Este efeito pode atuar tanto no sentido de oferecer a sensação de pertencimento a um grupo, como de fortalecer tal grupo para originar uma ação. As músicas Bate Poeira e Você não vai parecem atuar exatamente neste ponto. Conka transmite a empatia, se coloca como parte do grupo excluído. Ao associar o diferente a sua personalidade autoproclamada forte e enérgica o efeito pode ser empoderador, oferecendo a hipótese de outros como ela também serem assim e terem a possibilidade de crescer e se elevar em meio ao preconceito e a ideias conservadoras.

É importante destacar a relevância social de manifestar a celebração da diversidade de forma argumentativa em uma época de intolerância violenta. Se existe um padrão comercial conservador de beleza e identidade é fundamental que exista sua resistência, seu contraponto, e a argumentação pelo pathos eleva essa resistência a um debate com emoção, com possibilidade de induzir o convencimento e a compaixão. Enaltecer a diferença e a força da periferia como ato libertário é empoderador, é uma forma emocional de discurso que institui a argumentação além do convencional. Isso pode significar outros olhares de mundo e a ressignificação do que é valor para o sujeito, culminando na autocompaixão e na empatia.

\section{REFERÊNCIAS BIBLIOGRÁFICAS}

AMOSSY, Ruth. Argumentação e análise do discurso: perspectivas teóricas e recortes disciplinares. Trad. Eduardo Lopes Piris e Moisés Olímpio Ferreira. EID\&A-Revista Eletrônica de Estudos Integrados em Discurso e Argumentação, Ilhéus, n.1, p. 129-144, nov. 2011. Disponível em: <http://periodicos.uesc.br/index.php/eidea/article/view/389>. Acesso em: 10 dez. 2017.

BOCK, Lia. Girl crush: Karol Conka e Maria Ribeiro. Revista Trip. Disponível em: $<$ https://revistatrip.uol.com.br/tpm/karol-conka-e-maria-ribeiro-monogamia-racismo-filhos-eantidepressivos>. Acesso em: 6 jan. 2018.

CHARAUDEAU, Patrick. A patemização na televisão como estratégia de autenticidade. In: MACHADO, I. L.; MENEZES, W.; MENDES, E. (Orgs.). As emoções no discurso. Volume II. Campinas, SP: Mercado das Letras, 2010.

Linguagem e discurso: modos de organização. São Paulo: CONTEXTO, 2008.

Pathos e discurso politico in Ida Lucia Machado, William Menezes, Emilia Mendes (org.), As Emoções no Discurso, Volume 1. Rio de Janeiro : Lucerna, 2007. p. 240-251, 2007.

DEERE, Carmen Diana; LEÓN, Magdalena. O empoderamento da mulher: direitos à terra e direitos de propriedade na América Latina. Porto Alegre: Ed. da Universidade (UFRGS), 2002.

HERSCHMANN, Micael. O funk e o hip hop invadem a cena. 2. ed. Rio de Janeiro: Editora UFRJ, 2005. 
MAGRO, Viviane Melo de Mendonça. Adolescentes como autores de si próprios: cotidiano, educação e o hip hop. Cad. CEDES [online]. 2002, vol. 22, n. 57, p. 63-75.

NIELSEN. Mid-year report. Disponível em:

<http://www.nielsen.com/content/dam/corporate/us/en/reports-downloads/2017reports/music-us-mid-year-report-2017.pdf> Acesso em: 20 dez. 2017.

SOUZA, Ana Lúcia Silva. Letramentos de Reexistência: culturas e identidades no movimento hip-hop. Tese (Doutorado em Linguística Aplicada) - Universidade Estadual de Campinas, Instituto de Estudos da Linguagem. São Paulo, 2009.

SOUZA, Wander Emediato de. Retórica, argumentação e discurso. In: MARI, H. et. alii. Análise do discurso: fundamentos e práticas. Belo Horizonte: UFMG, 2001.

Submetido em 29/06/2019

Aceito em 10/01/2019

Publicado em 29/07/2019 